\title{
Efficacy of nanoceria for periodontal tissues alteration in glutamate-induced obese rats - multidisciplinary considerations for personalized dentistry and prevention
}

\author{
Tetyana V. Beregova ${ }^{1} \cdot$ Karine S. Neporada $^{2} \cdot$ Maksym Skrypnyk $^{2}$. \\ Tetyana M. Falalyeyeva ${ }^{1}$ - Nadiya M. Zholobak $^{3}$ • Oleksandr B. Shcherbakov ${ }^{3}$. \\ Mykola Ya. Spivak ${ }^{3,4}$ • Rostyslav V. Bubnov ${ }^{3,5}$
}

Received: 11 November 2016 / Accepted: 13 February 2017 /Published online: 14 March 2017

(C) European Association for Predictive, Preventive and Personalised Medicine (EPMA) 2017

\begin{abstract}
Background Nowadays, we face the global epidemic of obesity, that is known to contribute to the development of many diseases, such as the oral cavity pathologies. Dental and oral pathologies are frequently caused by and overlapped with systemic multifactorial diseases such as obesity being its early indicators and risk factors.

The aim was to study the influence of nanoceria on periodontal tissues alteration in glutamate (MSG)-induced obese rats.

Methods We included 52 Wistar rats of both genders and divided into four groups: newborn rats in group 1 (control) received subcutaneously $8 \mu \mathrm{l} / \mathrm{g}$ saline. Group 2 received 3 to $4 \mathrm{mg} / \mathrm{g}$ MSG subcutaneously on the second, fourth, sixth, eighth, and tenth day of life; group 3-intragastric administration of nanocrystalline cerium dioxide at a dose of $1 \mathrm{mg} / \mathrm{kg}$ volume of $2.9 \mathrm{ml} / \mathrm{kg}$ against the background of glutamateinduced obesity; the fourth group of animals was treated with
\end{abstract}

a solution of sodium citrate intragastric volume of $2.9 \mathrm{ml} / \mathrm{kg}$ (solvent of nanocrystalline cerium). We determined the total proteolytic activity, the total antitrypsin activity, the contentfree fucose and glycosaminoglycanes (GAG), content of TBA-active of products, the content of oxidation-modified proteins (OMB), and catalase activity in the homogenate of soft periodontal tissues of rats.

Results Intragastric injection of nanoceria prevents activation of proteolytic processes, reducing the catabolism of glycoproteins and proteoglycans of periodontal tissue in MSG-induced obese rats. Injection of nanoceria prevents activation of proteolytic processes, significantly decreases the total proteolytic activity, and inhibits the activation of free radical oxidation in periodontal tissues of rats compared with MSG-induced obesity model without corrections. Further, it significantly increases the total antitrypsin activity in periodontal tissues by 1.7 times, TBA-reagents by 1.7 times, and content of OMB by 1.4 times compared with glutamate-induced obese animals.

Mykola Ya. Spivak

n.spivak@ukr.net

Taras Shevchenko National University of Kyiv, Volodymyrska Str., 64/13, Kyiv 01601, Ukraine

2 Poltava Ukrainian Medical and Stomatological Academy, 23 Shevchenko str., Poltava 36024, Ukraine

3 Zabolotny Institute of Microbiology and Virology, National Academy of Sciences of Ukraine, Zabolotny Str., 154, Kyiv 03143, Ukraine

4 LCL 'DIAPROF’, Svitlycky Str., 35, Kyiv 04123, Ukraine

5 Clinical Hospital 'Pheophania' of State Affairs Department, Zabolotny str., 21, Kyiv 03143, Ukraine

Oleksandr B. Shcherbakov

carotene@mail.ru 
Conclusions MSG-induced obesity triggers periodontal tissue alterations in the rat model. Nanoceria contributes to the corrections of pathological changes in periodontal tissues in glutamate-induced obese rats via balancing proteininhibitory capacity and reducing the depolymerization of fucosylated proteins and proteoglycans and antioxidative activity.

Keywords Predictive preventive personalized medicine Nanocrystalline cerium dioxide $\cdot$ Nanoceria $\cdot$ Obesity $\cdot$ Oral cavity $\cdot$ Periodontal tissues $\cdot$ Fucoproteins $\cdot$ Proteoglycans · Glycosaminoglycanes · Antitrypsin activity $\cdot$ Antioxidative activity $\cdot$ Obesity complications $\cdot$ Monosodium glutamate Food additives $\cdot$ Animal model $\cdot$ Personalized dietology

\section{Overview}

\section{Predictive, preventive, and personalized dentistry: new concepts in obesity management and personalized nutrition}

Nowadays, we face the global epidemic of obesity, metabolic syndrome and diabetes type 2-twenty-first century disaster; the problem of obesity has become non-infectious pandemic status because according to WHO more than a billion people in the world are overweight. The number of people with obesity was projected doubled by 2025 [1]. Obesity and metabolic syndrome has been profoundly studied by experts of the European Association for Predictive, Preventive and Personalised Medicine (EPMA) [2-7], and effective solutions by predictive, preventive and personalized medicine (PPPM) were consequently suggested considering a sensitive balance between health and disease in individuals; environmental factors in epidemics and an interplay between a genetic component, epigenetic regulations, and environmental factors [4]. In Ukraine, more than a half of the adult population is overweight, which is certainly due to the low level of physical activity, eating behavior features, increase in diet-dense foods and carbohydrate and wide and uncontrolled use of food industry and online catering food additives, especially monosodium glutamate (MSG) [8].

The novel PPPM concepts have been suggested by EPMA to benefit the impacts on the oral and dental health [9-11]. It is well known that obesity interferes with dental practice and contributes to the development of many diseases, particularly in the oral cavity $[12,13]$. Dental and oral pathologies are both also early indicators and risk factors for a variety of multifactorial diseases [4] and are frequently caused/overlapped by for a variety of systemic diseases such as obesity and diabetes mellitus. Therefore, investigation of the cause-and-effect relationships between oral and dental diseases on the one hand and multifactorial systemic disorders on the other hand is a prerequisite for predictive, preventive, and personalized medicine in the multidisciplinary fields of dental and oral health care [4].

$M S G\left(\mathrm{C}_{5} \mathrm{H}_{8} \mathrm{NO}_{4} \mathrm{Na}, \mathrm{E} 621\right)$ is the most common food additive widely distributed and is naturally occurring in various foods (bouillon cubes, meat tenderizers, canned food, frozen food, potato and snack chips, barbecue sauce, salad dressing, soups, fast food, etc.) [14]. MSG is used to preserve the nutritional quality of food, providing them with better taste, increased technological processing of food raw materials, reduction and reduction process [14]. Now, it is hard to find industrially produced canned or semi-finished products that do not include MSG. Thus, the permissible limits may be significantly exceeded, which can lead to diseases of the digestive tract and include oral cavity. Obesogenic properties of monosodium glutamate were studied for decades [15-20]. Recently, we have studied monosodium glutamate-induced obesity and concluded that the introduction of MSG to newborn rats may cause the obesity in adulthood [21], and also studied the salivary glands abnormalities related to MSGinduced obesity $[22,23]$, and discussed the related concerns for modern nutrition and suggested opportunities for prevention via periodic probiotic mixture administration [21].

Periodontal tissues (periodontium) consist of four principal components, namely [24] gingiva, periodontal ligament (PDL), cementum, and alveolar bone proper. This anatomical complex is vulnerable to infections, chronic inflammation, and periodontal destruction leading to loosening or loss of teeth. Molecular matrix in periodontal connective tissue is a source of number of potential biomarkers [9, 23-27].

Nanocrystalline cerium dioxide (ceria nanoparticles nanoceria, $\mathrm{NCD}, \mathrm{nCeO} 2$ ) is well-known as antioxidant potentially effective for various biological applications [28-34].

However, so far, the mechanisms of pathological changes in periodontal tissues under the experimental obesity remain unclear as well the ability to correct these changes with nanoceria.

The aim of this study was to evaluate protective properties of nanoceria on periodontal tissues alterations, antioxidative activity, protein-inhibitory capacity, and efficacy to reduce depolymerization of fucosylated proteins and proteoglycans under conditions of glutamate-induced obesity in rats.

\section{Methods}

Research was conducted in compliance with the standards of the Convention on Bioethics of the Council of Europe's 'Europe Convention for the Protection of Vertebrate Animals' used for experimental and other scientific purposes' (1997), the general ethical principles of animal experiments, approved by the First National Congress on Bioethics Ukraine (September 2001) and other international agreements and national legislation in this field. Animals were kept in a vivarium that was accredited in accordance with the "standard rules on 
ordering, equipment and maintenance of experimental biological clinics (vivarium)." Instruments to be used for research are subject to metrological control.

Experiments were performed on 52 rats of both genders. The animals were divided into the following four groups: I-intact control (4-month rat) newborn rats; group II subcutaneously in a volume of $4 \mathrm{mg} / \mathrm{g}$ MSG administered at 2, 4, 6, 8, 10 day life; group III-intragastric administration of nanocrystalline cerium dioxide [21] at a dose of $1 \mathrm{mg} / \mathrm{kg}$ volume of $2.9 \mathrm{ml} / \mathrm{kg}$ against the background of glutamate-induced obesity, the fourth group of animals treated with a solution of sodium citrate intragastrically in volume of $2.9 \mathrm{ml} / \mathrm{kg}$ (solvent of nanocrystalline cerium). Introduction of nanocrystalline cerium dioxide solution starting from 4 weeks after birth (after weaning from the mother) and continued intermittently 2 -week course in 2 weeks.

During 4 months, the changes in a body weight were analyzed in rats of all groups. Four-month-old animals were decapitated, removed and weighed visceral fat was measured. Body length was measured; body mass index (BMI) (the ratio of body weight $(\mathrm{g})$ of rats to the square of the body length $\left(\mathrm{cm}^{2}\right)$ ) and Lee obesity index (the ratio of 1/4 of cube root of body weight ( $\mathrm{g}$ ) to body nose-to-anus length $(\mathrm{cm})$ ) were calculated as in [21]. Soft periodontal tissues of rats were excised, minced, treated with collagenase, homogenized, and centrifuged. We determined the total proteolytic activity, the total antitrypsin activity, the content-free fucose and glycosaminoglycanes (GAG), the levels of nitrites anions, and general activity of NO-synthase [12]. Development of oxidative stress in the periodontal tissues of rats was evaluated: the content of TBA-active of products, the content of oxidation-modified proteins (OMB), and catalase activity were measured in the rat periodontal tissues homogenate.

We used the non-parametric Mann-Whitney $U$ test, comparing two groups of independent samples of observations. All results are expressed as the $\mathrm{M} \pm \mathrm{SD}$ of $\mathrm{n}$ values. Differences were considered significant at $P$ values $<0.05$.

\section{Results}

We observed the development of visceral obesity in 4-month MSG rats that was confirmed by the increase of the VAT mass by $404 \%(p<0.001)$ in male and $287 \%(p<0.001)$ in female (Fig. 1). In $\mathrm{MSG}+\mathrm{nCeO}_{2}$ group, we established the decrease of visceral obesity. The VAT mass in MSG-group vs. MSG + nCeO2 group lowered to $19.0 \pm 2.0 \mathrm{~g}$ vs. $8.3 \pm 1.4 \mathrm{~g}, P<0.05$ in male and $16.5 \pm 2.6 \mathrm{~g}$ vs. $9.9 \pm 1.3 \mathrm{~g}, P<0.05$ in female rats.

We suppose that MSG-induced obesity induce an imbalance of proteinase-inhibitory potential of periodontal tissues, as evidenced by a significant increasing the total proteolytic activity by 2.4 times against the background of a fair reduction in the total antitrypsin activity compared to control animals (Table 1). It is possible due to the development protease

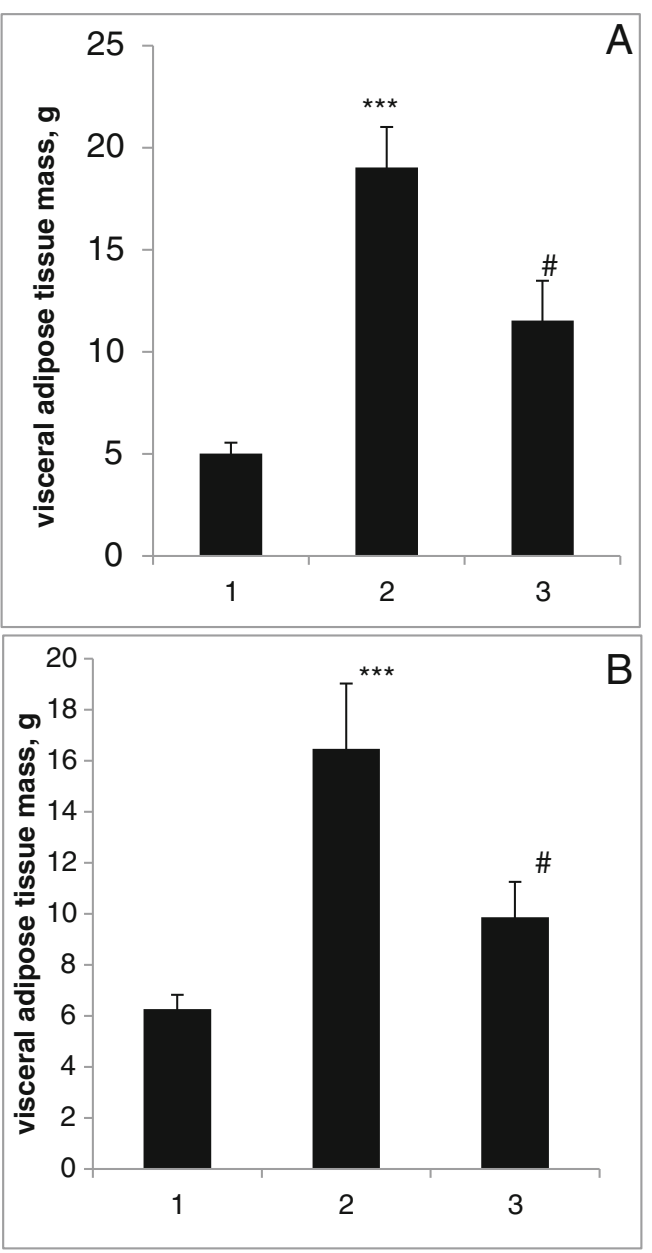

Fig. 1 Visceral adipose tissue mass in condition of MSG-obesity and $\mathrm{nCeO}_{2}$ treatment. a Male. b Female. $* * * P<0.001$ in comparison with group 1. $\# P<0.05$ in comparison with group 2. 1 Control. 2 MSG. 3 $\mathrm{MSG}+\mathrm{nCeO}_{2}$

inhibitors imbalance in periodontal tissues by decompensation type under the experimental obesity.

Intragastric injection of nanocrystalline cerium dioxide prevents activation of proteolytic processes in periodontal tissues of rats, evoked a significant decrease in total proteolytic activity compared with animals with modeled glutamate-induced obesity without treatment (Table 1). Under these conditions, the total antitrypsin activity of periodontal tissues was significantly increased (by 1.7 times) compared to animals with modeled glutamate-induced obesity without treatment (Table 1).

Thus, the injection of nanocrystalline cerium dioxide proteinase-inhibitor normalizes imbalances in the periodontal tissues of rats under the experimental obesity.

We have detected that the introducing MSG to newborn rats contributes to biopolymers depolimerization in periodontal connective tissue in rats, yields a significant increase of free fucose content by 1.8 times and levels of GAG by 1.7 times compared to the controls (Table 2). Intragastral injection of nanoceria prevents increasing the catabolism of fucoproteins and proteoglycans of connective tissue and periodontal 
Table 1 Proteinase-inhibitory potential of rat periodontal tissues under conditions of glutamateinduced obesity and correction by $\mathrm{NCD}(\mathrm{M} \pm \mathrm{m})$

\begin{tabular}{lll}
\hline Groups of animals & Total proteolytic activity, $\mathrm{g} / \mathrm{kg}$ & Total antitrypsin, $\mu \mathrm{mol} / \mathrm{g} * \min$ \\
\hline 1. Control $(\mathrm{n}=18)$ & $26.02 \pm 2.41$ & $0.21 \pm 0.14$ \\
2. Obesity $(\mathrm{n}=16)$ & $13.20 \pm 3.82^{*}$ & $0.51 \pm 0.09 *$ \\
3. Obesity + NCD $(\mathrm{n}=12)$ & $22.22 \pm 2.02 * *$ & $0.35 \pm 0.03 * *$ \\
4. Obesity + NCD solvent $(n=6)$ & $14.44 \pm 2.23$ & $0.31 \pm 0.04$ \\
\hline
\end{tabular}

$* P_{1-2}<0.05 ; * * P_{3-4}<0.05$ conditions after the injection of MSG. We have monitored a reduction in the content of free fucose by two times and of GAG in tissues by 1.8 times in periodontal tissues after introduction of MSG and nanocrystalline cerium dioxide compared to the controls (Table. 2).

The glutamate-induced obesity significantly increases the overall NO-synthase activity in rats' periodontal tissues by 1.57 times the content of nitrite anion by 1.3 times compared to the controls (Table 3). Thus, in periodontal tissues of glutamate-induced obese rats, the activation of NO-ergic system causes the development of oxidative stress through the formation of cytotoxic peroxynitrite. Intragastric treatment with nanoceria significantly reduces the total NO-synthase activity and nitrite anions content in periodontal tissues compared to the group of animals without correction (Table 3).

Thus, nanocrystalline cerium dioxide under the experimental obesity prevents periodontal tissue activation NO-ergic system.

MSG-induced experimental obesity contributes to the activation of free radical oxidation in periodontal tissues, as evidenced by the significant increase of the content of TBAreagents by almost 2 times and content of OMB by 1.7 times compared to controls (Table. 4). Under these conditions, catalase activity significantly decreased by 1.5 times in periodontal tissues compared to control animals (Table 4).

Thus, the experimental obesity in periodontal tissues triggers pro-antioxidant imbalance that causes the development of oxidative stress.

Intragastric treatment of glutamate-induced obesity with nanoceria inhibits the activation of free radical oxidation in rat periodontal tissues, as evidenced by the likely reduction of TBA-reagents by 1.7 times and content of OMB by 1.4 times compared to animals without correction (Table. 4). Nanoceria injection significantly increased catalase activity by 1.6 times compared to animals without correction (Table 4).

\section{Discussion}

To our knowledge, this is the first study demonstrating an efficacy of nanoceria producing periodontal tissue alterations in glutamate-induced obese rats, changing the molecular setup in periodontal tissue, and creating working hypothesis for multidisciplinary considerations in personalized dentistry and prevention. Periodontium connective tissue is a source of number of potentially routine biomarkers in diagnosing oral pre-malignant conditions, lesions, and malignancies [25], e.g., fucose and protein bound hexoses can be used as markers. Fucose is a deoxyhexose that is present in a wide variety of mammals; fucose-containing glycans have important roles in blood transfusion reactions, selectin-mediated leukocyte-endothelial adhesion, host-microbe interactions, and numerous ontogenic events, including signaling events by the Notch receptor family [25]. Fucoproteins and proteoglycans of connective tissue with serum glycoconjugates can be diagnostic and or prognostic marker in oral submucous fibrosis (OSMF), Leukoplakia and Oral Cancer, do have a significant diagnostic and prognostic value in these diseases [26]. Fucosylation of glycoproteins at terminal ends is one of the most important features that mediate several specific biological functions; tumor cells modulate their surface by increasing fucosylation levels to escape recognition, thus contributing to decreased adhesion and uncontrolled tumor growth [27].

Potential biomedical applications of nanocrystalline cerium dioxide has been widely studied [28-34]. Nanoceria was proved to be able to participate in biological processes as a
Table 2 Fucose content and GAG in rat periodontal tissues under conditions of glutamateinduced obesity and correction by $\mathrm{NCD}(\mathrm{M} \pm \mathrm{m})$

\begin{tabular}{lll}
\hline Groups of animals & Fucose level, $\mu \mathrm{mol} / \mathrm{g}$ & GAG level, $\mu \mathrm{mol} / \mathrm{g}$ \\
\hline 1. Control $(n=18)$ & $3.40 \pm 0.36$ & $0.49 \pm 0.16$ \\
2. Obesity $(n=16)$ & $6.22 \pm 1.58^{*}$ & $0.85 \pm 0.19^{*}$ \\
3. Obesity + NCD $(n=12)$ & $3.11 \pm 0.22^{* *}$ & $0.46 \pm 0.30^{* *}$ \\
4. Obesity $+\mathrm{NCD}$ solvent $(n=6)$ & $3.15 \pm 0.14$ & $0.45 \pm 0.18$ \\
\hline
\end{tabular}

$* P_{1-2}<0.05 ; * * P_{3-4}<0.05$ 
Table 3 NO-ergic system in rat periodontal tissues under conditions of glutamate-induced obesity and correction by NCD $(\mathrm{M} \pm \mathrm{m})$

\begin{tabular}{lll}
\hline Groups of animals & $\begin{array}{l}\text { The total NO-synthase } \\
\text { activity, [NO2- }] / \mathrm{g} / \mathrm{min}\end{array}$ & $\begin{array}{c}\text { Content of nitrite } \\
\text { anions, } \mathrm{mmol} / \mathrm{g}\end{array}$ \\
\hline 1. Control $(n=18)$ & $1.94 \pm 1.03$ & $0.48 \pm 0.10$ \\
2. Obesity $(n=16)$ & $3.06 \pm 0.9^{*}$ & $0.63 \pm 0.10^{*}$ \\
3. Obesity $+\mathrm{NCD}(n=12)$ & $1.65 \pm 0.63^{* *}$ & $0.44 \pm 0.07^{* *}$ \\
4. Obesity + NCD solvent $(n=6)$ & $1.54 \pm 0.74$ & $0.51 \pm 0.077$ \\
\hline$P_{1-2}<0.05 ; * P_{3-4}<0.05$ & &
\end{tabular}

regulator of reactive oxygen species and free radicals acceptor [28]; and its efficacy for number of biomedical applications namely age-related male infertility [31], gastrointestinal motility with potential for prokinetic treatment and prevention in elderly [32], and efficacy for prophylaxis of erosive and stressinduced ulcerative lesions in the gastric mucosa of rats [33].

Current data contribute to the antioxidative theory of nanomedicine of cerim.

\section{Consolidation of the PPPM concept}

\section{Personalized medical approach and molecular mechanisms of nanocrystalline ceria effects in periodontal tissues}

The results of this study strongly support conclusions emphasised in our previous works [29-34, 37] and are potentially applicable to create products, drugs and food supplements for treatments beneficial for individual outcomes.

We suggest the follow-up studies considering functional links between oral diseases, obesity, metabolic disorders, and molecular patterns characteristic for obesity dietary additives, immune and inflammatory responses, in order to develop and test promising nanomaterials (nanoceria).

The results on nanoceria effects may be further considered for the vascular/microcirculation response, related to tissue microenvironment [35-37], that have particular importance for individuals in a suboptimal health condition such as "Flammer Syndrome" affected persons, and the strong potential for patient stratification [35] to avoid and optimally manage chronic diseases [36, 37].

Further studies including sufficient cohorts of volunteers are necessary to translate model data to human population. After approval, development of safe and effective personalized medications/additives, clinical testing should be initiated to implement results for routine practice.

\section{Predictive medical approach}

Translation of obtained results to human organism is quite a challenge $[11,21,31,32]$ and may allow to consider consumption of the products containing MSG, especially in early age, as a predictive value for obesity and metabolic syndrome development. Developing the panel of obesity assessment biomarkers is an important point.

Biomarkers from oral cavity $[6,11]$ might include fucoproteins and proteoglycans of connective tissue with serum glycoconjugates as the specific diagnostic and or prognostic biomarker panels in oral diseases [26] used for the patient stratification with variety of diseases by evaluation of saliva / oral cavity biomarkers to predict therapy responses [38].

\section{Microbiome of oral cavity}

Future research dedicated to the oral bacteria involved in the pathology and leading to obesity is needed [39] answering the question - how the salivary microbiology affects gastrointestinal microbiology. This sentiment is echoed by the great interest in orally administered exogenous bacteria (probiotic therapy) [40]. Oral diseases are linked to many immunerelated diseases like arthritis [41] via microbiome of the oral cavity.

Oral bacteria are known to contribute to the weight increase and development of obesity by at least three mechanisms [39]: (1) the oral bacteria may contribute to increased metabolic efficiency, (2) by increasing appetite, and (3) energy metabolism by
Table 4 Index of oxidative stress in rat periodontal tissues under conditions of glutamate-induced obesity and correction by NCD $(\mathrm{M} \pm \mathrm{m})$

\begin{tabular}{llll}
\hline Groups of animals & $\begin{array}{l}\text { The activity of } \\
\text { catalase, nkat/g }\end{array}$ & $\begin{array}{l}\text { OMB content, } \\
\mathrm{mmol} / \mathrm{g}\end{array}$ & $\begin{array}{l}\text { Content of TBA- } \\
\text { reagents, } \mu \mathrm{mol} / \mathrm{L}\end{array}$ \\
\hline 1. Control $(n=18)$ & $1.76 \pm 0.23$ & $0.109 \pm 0.04$ & $21.77 \pm 6.28$ \\
2. Obesity $(n=16)$ & $1.14 \pm 0.17^{*}$ & $0.186 \pm 0.019^{*}$ & $43.27 \pm 4.8^{*}$ \\
3. Obesity + NCD $(n=12)$ & $1.79 \pm 0.18^{* *}$ & $0.135 \pm 0.021^{* *}$ & $26.04 \pm 3.23^{* *}$ \\
4. Obesity + NCD solvent $(n=6)$ & $0.82 \pm 0.35$ & $0.121 \pm 0.016$ & $25.28 \pm 4.3$ \\
\hline
\end{tabular}

$* P_{1-2}<0.05 ; * * P_{3-4}<0.05$ 
facilitating insulin resistance through TNF $\alpha$ increasing levels or reducing levels of adiponectin.

\section{Preventive medical approach}

Obesity prevention by designing personalised diet corrections at early disease stages is a principle message towards preventive measures against obesity epidemic. However, the glutamate-induced effects in oral cavity that modify the taste sensation, oral microbiota, and sensitization of CNS [43] have to be be further studied.

\section{Diet and probiotics}

Significant correlations between body shape and periodontal disease demonstrated similarities to those observed in other obesityrelated health problems [42]. Translation of the currently obtained data on animal model to human organism should allow to consider dietary and probiotic tissues [44-46], probiotic strain impacts on pancreatic function, and insulin resistance for personalized dietology.

\section{Conclusions}

In our study performed on the obese rats, nanoceria demonstrates protective properties on periodontal tissues and normalization of the protein-inhibitory capacity, reduced depolymerization of fucosylated proteins and proteoglycans as well as srong antioxidative effects.

\section{Expert recommendations}

We recommend this study results to be considered for obesity complications in oral cavity and new concepts to be created in the context of predictive, preventive and personalized medicine such as personalized nutrition, overall management of obeisty as well as predicitve and preventive dentisry.

Treatment algorithms for patients suffering from obesity and follow-up cascade of chronic patologies have not been yet consolidated among the specialists in dentistry. We believe that current data will strongly contribute to the multi-professional considerations dedicated to the optimal management of obese and diabetic patients predisposed to or suffering from oral pathologies [47].

Acknowledgements We acknowledge the EPMA Journal editorial team for the opportunity to publish this work.

Authors' contributions NKS, FTM, and MS suggested an idea, performed experiments, and statistical analysis of obtained data and prepared the article. BTV did the organization and analysis of the study. NBZ and OBS conducted synthesis of nanoceria and adaptation to use in experiment. MYS did the organization and analysis of the study and prepared the article. RVB participated in the analysis of the study, did the literature review, prepared discussion, and formulated prospects and performed the second and final article drafting.

All authors read and approved the final manuscript.

Compliance with ethical standards All applicable international, national, and/or institutional guidelines for the care and use of animals were followed.

Competing interests The authors declare that they have no competing interests.

Funding The study was conducted with the support of the State Agency on Science, Innovations and Informatisation of Ukraine.

\section{References}

1. WHO: Obesity and overweight: Fact sheet N. 311. [http:// www.who.int/mediacentre/factsheets/fs311/en/] Accessed 12 Feb 2017.

2. Golubnitschaja O, Costigliola V, EPMA. General report \& recommendations in predictive, preventive and personalised medicine 2012: white paper of the European Association for Predictive, Preventive and Personalised Medicine. EPMA J. 2012;3(1):14.

3. Abraham J-A, Golubnitschaja O, Akhmetov I, Andrews RJ, Quintana L, et al. EPMA-World Congress 2015. EPMA J. 2016;7 Suppl 1:9.

4. Golubnitschaja O, Baban B, Boniolo G, Wang W, Bubnov R, Kapalla M, et al. Medicine in the early twenty-first century: paradigm and anticipation-EPMA position paper 2016. EPMA J. 2016;7:23. doi:10.1186/s13167-016-0072-4.

5. Golubnitschaja O, Costigliola V, EPMA. EPMA summit 2014 under the auspices of the presidency of Italy in the EU: professional statements. EPMA J. 6 (1):4.

6. Grech G, Zhan X, Yoo BC, Bubnov R, Hagan S, Danesi R, et al. EPMA position paper in cancer: current overview and future perspectives. EPMA J. 2015;6(1):9. doi:10.1186/s13167-015-0030-6.

7. Shapira N. Women's higher health risks in the obesogenic environment: a gender nutrition approach to metabolic dimorphism with predictive, preventive, and personalised medicine. EPMA J. 2013;4(1):1. doi:10.1186/1878-5085-4-1.

8. Stepanov Y, Skyrda I. Gastrointestinal care of in Ukraine: key health indicators and resources in 2011. Gastroenterology. 2013;1(46):8-11.

9. Cafiero C, Matarasso S. Predictive, preventive, personalised and participatory periodontology: 'the 5Ps age' has already started. EPMA J. 2013;4(1):16.

10. Tachalov VV, Orekhova LY, Kudryavtseva TV, Isaeva ER, Loboda ES. Manifestations of personal characteristics in individual oral care. EPMA J. 2016;7:8. doi:10.1186/s13167-016-0058-2.

11. Krapfenbauer K, Drucker E, Thurnher D. Identification of tumourrelated proteins as potential screening markers by proteome analysis-protein profiles of human saliva as a predictive and prognostic tool. EPMA J. 2014;5(1):20. doi:10.1186/1878-5085-5-20.

12. Kharma MY, Aws G, Tarakji B. Are dentists involved in the treatment of obesity? J Int Soc Prevent Commu Dentistry. 2016;6(3): 183-8. doi:10.4103/2231-0762.183112.

13. Ritchie CS. Obesity and periodontal disease. Periodontol 2000. 2007;44:154-63.

14. Ninomiya K. Natural occurrence. Food Rev Int. 1998;14(2 \& 3): 177-211. 
15. Olney JW. Brain lesions, obesity, and other disturbances in mice treated with monosodium glutamate. Science. 1969;164(3880): 719-21. doi:10.1126/science.164.3880.719.

16. Redding TW, Schally AV, Arimura A, Wakabayashi I. Effect of monosodium glutamate on some endocrine functions. Neuroendocrinology. 1971;8:245-55. doi:10.1159/000122011.

17. Miskowiak B, Partyka M. Effects of neonatal treatment with MSG (monosodium glutamate) on hypothalamo-pituitary-thyroid axis in adult male rats. Histol Histopathol. 1993;8(4):731-4.

18. Afifi MM, Abbas AM. Monosodium glutamate versus diet induced obesity in pregnant rats and their offspring. Acta Physiol Hung. 2011;98(2):177-88.

19. Leshchenko IV, Shevchuk VH, Falalieieva TM, Beregova TV. [The influence of long-term monosodium glutamate feeding on the structure of rats pancreas]. Fiziol Zh. 2012;58(2):59-65. Ukrainian.

20. Falalieieva TM, Kukhars'ky̆ VM, Berehova TV. [Effect of longterm monosodium glutamate administration on structure and functional state of the stomach and body weight in rats]. Fiziol $\mathrm{Zh}$. 2010;56(4):102-10. Ukrainian.

21. Savcheniuk OA, Virchenko OV, Falalyeyeva TM, Beregova TV, Babenko LP, Lazarenko LM, et al. The efficacy of probiotics for monosodium glutamate-induced obesity: dietology concerns and opportunities for prevention. EPMA J. 2014;5:2.

22. Beregova TV, Falalyeyeva TM, Neporada KS, Gordienko LP. Metabolic changes in salivary glands of rats under glutamateinduced obesity. J Dent Oral Disord Ther. 2014;2(3):1-4.

23. Hordiienko LP, Berehova TV, Neporada KS, Falalieieva TM. Oxidative stress development in the tissues of salivary glands of rats in conditions of monosodium glutamate-induced obesity. Fiziol Zh. 2014;60(4):105-7. Ukrainian.

24. Nanci A, Bosshardt DD. Structure of periodontal tissues in health and disease. Periodontol 2000. 2006;40:11-28

25. Becker DJ, Lowe JB. Fucose: biosynthesis and biological function in mammals. Glycobiology. 2003;13(7):41R-53. doi:10.1093/ glycob/cwg054.

26. Bose KSC, Gokhale PV, Dwivedi S, Singh M. Quantitative evaluation and correlation of serum glycoconjugates: protein bound hexoses, sialic acid and fucose in leukoplakia, oral sub mucous fibrosis and oral cancer. J Nat Sci Biol Med. 2013;4(1):122-5. doi:10.4103/ 0976-9668.107275.

27. MacDougall SL, Schwarting GA, Parkinson D, Sullivan AK. Increased fucosylation of glycolipids in a human leukaemia cell line (K562-Clone I) with decreased sensitivity to NK-mediated lysis. Immunology. 1987;62(1):75-80.

28. Karakoti AS, Monteiro-Riviere NA, Aggarwal R, Davis JP, Narayan RJ, Self WT, et al. Nanoceria as antioxidant: synthesis and biomedical applications. JOM (1989). 2008;60(3):33-7.

29. Zholobak NM, Sherbakov AB, Babenko LS, Bogorad-Kobelska OS, Bubnov RV, Ivanov VK et al. The perspectives of biomedical application of the nanoceria. EPMA J. 2014;5 Suppl 1:A136. doi: 10.1186/1878-5085-5-S1-A136.

30. Zholobak NM, Mironenko AP, Shcherbakov AB, Shydlovska OA, Spivak MY, Radchenko LV et al. Cerium dioxide nanoparticles increase immunogenicity of the influenza vaccine. Antiviral Res. 2016;127:1-9. doi:10.1016/j.antiviral.2015.12.013.

31. Kobyliak NM, Falalyeyeva TM, Kuryk OG, Beregova TV, Bodnar PM, Zholobak NM, et al. Antioxidative effects of cerium dioxide nanoparticles ameliorate age-related male infertility: optimistic results in rats and the review of clinical clues for integrative concept of men health and fertility. EPMA J. 2015;6:12. doi:10.1186/ s13167-015-0034-2.

32. Yefimenko OY, Savchenko YO, Falalyeyeva TM, Beregova TV, Zholobak NM, Spivak MY, et al. Nanocrystalline cerium dioxide efficacy for gastrointestinal motility: potential for prokinetic treatment and prevention in elderly. EPMA J. 2015;6:6.

33. Golyshkin D, Kobyliak N, Virchenko O, Falalyeyeva T, Beregova T, Ostapchenko L, et al. Nanocrystalline cerium dioxide efficacy for prophylaxis of erosive and ulcerative lesions in the gastric mucosa of rats induced by stress. Biomed Pharmacother. 2016; doi:10.1016/ j.biopha.2016.10.060.

34. Iefimenko OY, Savchenko IO, Falalyeyeva TM, Beregova TV, Zholobak NM, Shcherbakov OB, et al. The influence of nanodisperse cerium dioxide on ontogenetic changes of antioxidant system in the mucosa of the stomach and colon in rats. Fiziol $\mathrm{Zh}$. 2015;61(3):44-50. Ukrainian.

35. Flammer J, Konieczka K, Flammer AJ. The primary vascular dysregulation syndrome: implications for eye diseases. EPMA J. 2013;4(1):14.

36. Golubnitschaja O, Debald M, Kuhn W, Yeghiazaryan K, Bubnov RV. Flammer syndrome and potential formation of pre-metastatic niches: a multi-centred study on phenotyping, patient stratification, prediction and potential prevention of aggressive breast cancer and metastatic disease. EPMA J. 2016;7 Suppl 1:A25. doi:10.1186/ s13167-016-0054-6.

37. Bubnov RV, Kobyliak NM, Zholobak NM, Spivak MY. Ultrasound for stratification patients with diabetic foot ulcers for prevention and personalized treatment - pilot results. EPMA J. 7 (Suppl 1), A13. doi:10.1186/s13167-016-0054-6.

38. Qin X, Liu JY, Abdelsayed R, Shi X, Yu JC, Mozaffari MS, et al. The status of glucocorticoid-induced leucine zipper protein in the salivary glands in Sjögren's syndrome: predictive and prognostic potentials. EPMA J. 2016;7:3. doi:10.1186/s13167-016-0052-8.

39. Goodson JM, Groppo D, Halem S, Carpino E. Is obesity an oral bacterial disease? J Dent Res. 2009;88(6):519-23. doi:10.1177/ 0022034509338353.

40. Bisanz JE, Suppiah P, Thomson WM, Milne T, Yeoh N, Nolan A, et al. The oral microbiome of patients with axial spondyloarthritis compared to healthy individuals. Peer J. 2016;4:e2095. doi:10. 7717/peerj.2095.

41. Socransky SS, Haffajee AD. Periodontal microbial ecology. Periodontol 2000. 2005;38:135-87.

42. Wood N, Johnson RB, Streckfus CF. Comparison of body composition and periodontal disease using nutritional assessment techniques: Third National Health and Nutrition Examination Survey (NHANES III). J Clin Periodontol. 2003;30(4):321-7.

43. Pastukhov A, Krisanova N, Maksymenko V, Borisova TA. Personalized approach in brain protection by hypothermia: Individual changes in non-pathological and ischemia-related glutamate transport in brain nerve terminals. EPMA J. 2016;7:25.

44. Bubnov RV, Spivak MY, Lazarenko LM, Bomba A, Boyko NV. Probiotics and immunity: provisional role for personalized diets and disease preventio. EPMA J. 2015;6:14.

45. Babenko LP, Sokolviak OY, Mokrozub VV, Nechypurenko OO, Demchenko OM, Bubnov RV, Lazarenko LM, Spivak MY. Lactobacillus and Bifidobacterium probiotic strains reduce cholesterol levels and affect the gut microbiota in obese mice. United Europ Gastroenterol J. 2016;4(5S):A374-5.

46. Tuffrey V, Krikser T, Trichopoulou A, Fakir AM, Bubnov RV, Bishwajit G. Modern Nutrition and Food Hygiene. 07/2016; Scientific Research Publishing, Inc., USA. (2016)., ISBN: 978-161896-161-7; ISBN: 978-1-61896-160-0.

47. Borkowski DS, Zhuravel VV, Bubnov RV. Target approach for prevention activities in dental service of closed government systems. Ukrainian concept. EPMA J. 2014;5 Suppl 1:A126. 